\title{
SPECTROPHOTOMETRIC DETERMINATION OF RUTHENIUM PRESENT IN TRACES
}

\author{
P. P. Sinha ${ }^{1}$, S.K.S. Tomer ${ }^{2}$, A. Asthana ${ }^{3}$ \\ ${ }^{1}$ Department of Applied Science, Ambalika Institute of Management and Technology, Lucknow \\ ${ }^{2}$ Department of Applied Science, Ambalika Institute of Management and Technology, Lucknow \\ ${ }^{3}$ Department of Applied Science, Ambalika Institute of Management and Technology, Lucknow
}

\begin{abstract}
Phenanthraquinone monothiosemicarbazone (PTS) has been used in the determination of ruthenium by spectrophotometric method. PTS forms a green complex with ruthenium (III) at pH 5.2 to 6.7. The complex is soluble in DMF. The maximum absorbance of the complex has been found at $660 \mathrm{~nm}$. The complex has been found to obey Beers Law up to 9.38 ppm. Effect of diverse ions in the determination of ruthenium has also been studied. Attempts have been made to mask the various interfering cations by anions. The sensitivity of the method is $0.0102 \mu \mathrm{g} \mathrm{Ru} / \mathrm{cm}^{2}$ at $660 \mathrm{~nm}$
\end{abstract}

Keywords - DMF, Phenanthraquinone monothiosemicarbazone (PTS), ruthenium (III), spectrophotometric

$* * *$

\section{INTRODUCTION}

Various reagents for the spectrophtometric determination of ruthenium have been reported in various reviews and texts (1-3). A few well known reagents for the determination of ruthenium are 1,4- and 2,4- diphenylthiosemicarbazide, thiourea, 1,10- phenanthroline, 2,4,6- tri( 2'-pyridyl )-5triazine (TPTZ), isonitrsobenzoylacetone, thiocyanate, pnitrosodimethl aniline,3- hydroxyl-2-methyl-1-,4naphthoquinone monoxime, o-toludine, chrome azurol $\mathrm{S}$, anthranilic acid, tropolone, acenaphthenequinonemonoxime, fusion method, acetlyacetone hydroxyiminoacetyllacetone, etc.

In the present work, it was observed that ruthenium (III) forms a green complex with Phenanthraquinone monothiosemicarbazone (PTS) only on heating a mixture of the reactants on a water bath. Effect of several variables such as $\mathrm{pH}$, temperature, concentration of the reagent etc. on ruthenium-PTS complex has been studied.

\section{EXPERIMENTAL}

\subsection{Preparation of PTS}

PTS was prepared by oxidation of phenanthrene ( Fluka, AG ) to phenanthraquinone by the method of Schultz and was purified. Then equimolar amounts of phenanthraquinone and thiosemicarbazide (E.Merck GR) were dissolved separately in minimum amounts of methanol and then mixed. After mixing, the solution was refluxed for three hours on a boiling water bath. The hot solution was filtered under suction and cooled. Red crystals of PTS were obtained which were recrystallised from methanol (m,p, 191-192). The purity of the ligand has been checked by elemental analysis and thin layer chromatography. The wavelength of maximum absorption of PTS is at pH 0.7, 6.5 and 11.9 is at 250, 254 and $207 \mathrm{~nm}$ respectively. PTS solution was prepared by dissolving it in dimethyl formamide (DMF) because its greater solubility in this solvent. The solution is stable for two days.

\subsection{Preparation of Ruthenium (III) Solution}

Standard ruthenium (III) solution was prepared by dissolving ruthenium (III) chloride (Jhonson Mattey, London) in doubly distilled water containing sufficient amount of hydrochloric acid to give the final concentration of $1 \mathrm{~N} \mathrm{HCl}$. Since the ruthenium (III) has a tendency to turn dark brown on keeping due to oxidation, the stock solution was obtained by refluxing for 4 hours with hydrochloric acid and ethanol. The ruthenium content was determined gravimetrically by precipitating ruthenium as the ruthenium hydroxide, followed by careful ignition in air. Subsequent solutions were made from the stock solution according to requirement.

\subsection{Absorption Spectra}

On mixing a solution of the ruthenium ion with the PTS in DMF in acidic medium, no colour formation took place. However on heating the contents on a water bath, a green precipitate appeared. The precipitate was dissolved in DMF in which the complex was completely soluble. Absorption spectra of the complex formed by $3.2 \times 10^{-5} \mathrm{M}$ ruthenium (III) solution and $3.2 \times 10^{-4} \mathrm{M}$ PTS at $\mathrm{pH} 5.9$ and $\mathrm{pH} 4.4$ was observed. The maximum absorbance was found at 660 $\mathrm{nm}$. Hence the subsequent studies have been carried out at this wavelength.

\subsection{Rate of Colour Development and Stability of the}

\section{Complex}

A study of the colour development has been carried out. The solutions were heated on different intervals of time and the absorbance was measured at $660 \mathrm{~nm}$. The absorbance was 
found to remain constant after heating for about 105 minutes. In view of these observations, in subsequent studies, the reaction mixture was heated for nearly two hours. The complex was found to be fairly stable and no change in absorbance was observed up to 20 hours.

\subsection{Effect of DMF}

Increasing amount of DMF was added to the complex and it was found to be soluble completely in $70 \%$ DMF medium. Higher percentage of DMF had no effect on the absorbance.

\subsection{Effect of pH}

The effect of $\mathrm{pH}$ on the formation of the complex has been investigated by preparing a series of solutions containing 2.5 $\mathrm{ml}$ of $3.2 \times 10^{-4} \mathrm{M}$ ruthenium (III) AND $2.5 \mathrm{ml}$ of $3.2 \times 10^{-3}$ $\mathrm{M}$ reagent in DMF. pH's of the solutions were adjusted at different levels by the addition of acetate buffer. For higher $\mathrm{pH}$ 's, dilute solution of sodium hydroxide was used. The solutions were heated for nearly two hours and after cooling, the total volume was raised to $25 \mathrm{ml}$ with doubly distilled water, maintaining 70\% DMF (v/v) in the medium. The apparent $\mathrm{pH}$ of this solution was taken to be the final $\mathrm{pH}$ of the system. Absorbance of these solutions, measured against the corresponding reagent blank. The absorbance remained constant between $\mathrm{pH} 5.2-6.7$.

\subsection{Effect of PTS Concentration}

A set of solutions containing constant amount of ruthenium (III) and varying amount of PTS in (1:1 to1:10 molar ratio) were prepared and absorbance were measured at $660 \mathrm{~nm}$ against corresponding blanks. It was found that at least five fold molar excess of PTS is required for maximum absorbance. However tenfold PTS was used in subsequent studies.

\subsection{Adherence to Beer's Law}

The system has been found to obey Beer's law up to 9.38 ppm of ruthenium. The sensitivity of the colour reaction, in terms of Sandell's definition is $1.02 \times 10^{-2} \mu \mathrm{g} / \mathrm{cm}^{2}$ for $\log$ $\mathrm{I}_{\mathrm{O}} / \mathrm{I}=0.001$. The molar extinction coefficient of the ruthenium complex comes out to be $9843.81 \mathrm{~mole}^{-1} \mathrm{~cm}^{-1}$. The optimum range for determination of ruthenium, as evaluated from Ringbom plot, is $2.00-7.08 \mathrm{ppm}$.

\section{RECOMMENDED PROCEDURE FOR DETERMINATION OF RUTHENIUM (III)}

Aliquots containing 50.0 - $177.0 \mu \mathrm{g}$ of ruthenium (III) are taken and tenfold molar excess of the reagent in DMF is added. The contents are buffered in the $\mathrm{pH}$ range $5.2-6.7$ by acetate buffer and then heated on water bath for about two hours. After cooling to room temperature, the volume is made up to $25 \mathrm{ml}$ with DMF and water so that the final solution contains $70 \%$ DMF ( v/v ). A blank containing all components except ruthenium is prepared in a similar way and absorbance of Ru - PTS complex is measured against the blank at $660 \mathrm{~nm}$. Knowing the absorbance, the amount of ruthenium is determined from the calibration curve.

\section{ABSORBANCE DEVIATIONS STOICHIOMETRY OF THE COMPLEX}

AND

The precision of the procedure was checked by measuring absorbance 0 eight samples, each containing of $80.75 \mu \mathrm{g}$ of ruthenium. The mean value of absorbance was found to be 0.315 at $660 \mathrm{~nm}$, with an average relative deviation of 0.32 $\%$ and standard deviation of $3.6 \times 10^{-3}$.

The molar composition of the complex was determined by Job's and Mole ratio methods. The formation of the complex from both of the said methods, corresponds to 1: 2 (Ru: PTS) complex.

\subsection{Effect of Diverse Ions}

A series of synthetic samples containing $3.23 \mathrm{ppm}$ of ruthenium ( III ) and known amounts of diverse ions were prepared and analysed by the recommended procedure. Attempts have been made to mask the various interfering cations by anions mentioned against them. The concentrations (in ppm) of various ions which did not cause deviations of more than $\pm 3 \%$ in absorbance are given below in parenthesis:

Chloride (600), bromide, nitrate and sulphate (400), iodide and oxalate (300 each), fluoride, tartarate and cyanide (50, each), borate (200), phosphate (100), thiocyanate (250), EDTA (40), thiossulphate (30), calcium (II ) (70), barium (II) and magnesium (II) (60 each) iron (II) (15, $\left.\mathrm{PO}_{4}^{-3}\right)$, cobalt (II) $\left(2, \mathrm{CN}^{-}\right)$, nickel (II) $\left(4, \mathrm{CN}^{-}\right)$, silver (I) $\left(15, \mathrm{Cl}^{-}\right)$, zinc (II) and cadmium (II) (5 each, $\mathrm{CN}^{-}$), mercury ( II ) ( 5, $\left.\mathrm{I}^{-}\right)$, palladium (II) $\left(2, \mathrm{CN}^{-}\right)$, osmium (VIII) $\left(1, \mathrm{CN}^{-}\right)$, iridium (III) $\left(10, \mathrm{SCN}^{-}\right)$, platinum (IV) $\left(4, \mathrm{I}^{-}\right)$, manganese (II) (15), uranyl (II) (70), aluminium (III) (5), vanadium (V) (5), lead (II) $\left(5, \mathrm{I}^{-}\right)$. Nitrate, copper (II) and rhodium (III) interfere seriously.

\section{DISCUSSION}

There are many organic reagents known for spectrophotometrc determination of ruthenium, but only few of them are suitable. 1,4-Diphenylthiosemicarbazide has been used for the determination of ruthenium. The disadvantage of this method is that before the dtermination, ruthenium should be separated as $\mathrm{RuO}_{4}$ by distillation or extraction, although it has the advantage that tenfold osmium can be determined.

The method based on the formation of a water soluble blue complex of ruthenium with thiourea, is simple but insensitive. The colour intensity depends on temperature, time heating and concentration, though the tolerance for iridium. rhodium, platinum and nickel offers some advantage.

Acetylacetone is not a very sensitive reagent and the effect of associated platinum metals has not been studied. Thiocyanate is a sensitive reagent but associated base and platinum metals interfere. The method involves extraction but oxidation to the tetroxide is a critical step. In case of $\mathrm{p}$ - 
nitrosodimethyl aniline, controlled conditions are required for full colour development and there is serious interference by osmium and nitrate, but the reagent is highly sensitive. Although 2, 4, 6-tri-(2'-pyridyl)-5-triazine is sensitive but it is less selective. Iron interferes seriously and also prior separation of ruthenium from other platinum metals is desirable.

Among the recently reported reagents for determination of ruthenium, 3-hydroxy-2-methyl-1, 4naphthoquinonemonoxime is quite sensitive and selective. Rhodium (III) and citrate interfere. The disadvantage of alkali fusion method is that platinum group metals interfere when present at $>1: 1(\mathrm{w} / \mathrm{w})$ ratio to ruthenium. The method using isonitrosobenzoylacetone requires only 3 minutes at $100^{\circ} \mathrm{C}$ for complete complexation, but has low sensitivity and iron, palladium and platinum interfere.

In most of the methods, known for the spectrophotometric determination of ruthenium, metals of Eighth group interfere and therefore prior separation is required. However in the present method, selectivity has been enhanced by use of masking agents. Except rhodium, other eighth group metals can be masked successfully .Moreover; strict control of $\mathrm{pH}$ is also not required as in case of thiourea and pnitrosodimethylaniline. There is no need of extraction and long heating as in case of acenaphthenequinonemonoxime. The sensitivity of this method is comparable with other sensitive methods.

\section{REFERENCES}

[1] Z. Marczenko, "Spectrophtometric Determination of Elements", John Wiley \& Sons Inc., New York, 1976

[2] E. S, Sandell and H. Onishi, "Colorometrc Determination of Traces of metals", Vol. 3, Part 1, John Wiley \& sons, Inc., New York, 1978.

[3] J. E. Currah, A. Fishel, W.A>E. McBryde and F.E. Beamish, ibid., 1952, 24, 1980 